\title{
Monitoring methods for skin dose in interventional radiology
}

\author{
Abdulhamid Chaikh ${ }^{1}$, Arnaud Gaudu2 ${ }^{2}$, Jacques Balosso ${ }^{1,3}$ \\ ${ }^{I}$ Department of Radiation Oncology and Medical physics, Grenoble University Hospital, France \\ ${ }^{2}$ Department of Radioprotection, Grenoble University Hospital, France \\ ${ }^{3}$ Department of Radiation Oncology and Medical physics, University Joseph Fourier, Grenoble, France
}

Received August 27, 2014; Revised November 08, 2014; Accepted November 08, 2014; Published Online November 29, 2014

\section{Review Article}

\begin{abstract}
Interventional radiology makes an increasing use of X-ray for diagnostic and therapeutic procedures. The dose received by the patient sometime exceeds the threshold value of deterministic effects, and this requires monitoring of the dose delivered to the patients. Delivered dose could be assessed through either direct or indirect methods. The direct methods use dosimeters that are placed on the skin during the procedure, whereas, the indirect methods are based on measured quantities derived from the equipment itself. Each method has its own limitations; however, the main concern is the ability to measure the dose more accurately due to complexity of the anatomical structures of the patient and the variable course of each procedure. This review article summarizes the principle and main advantages and disadvantages of each method. A comparison of the performances of each method for interventional fluoroscopy and radiography in its ability to monitor the patient's skin dose is provided.
\end{abstract}

Keywords: Skin Dose; Interventional Radiology; Dosimeters; Fluoroscopy; Radiography

\section{Introduction}

The present development of interventional radiology with fluoroscopic installations introduces a very large and somehow uncontrolled use of variable doses of X-ray. Conversely, regular radiographic procedures are typically automatic and optimized to deliver the lowest X-ray dose as possible. Also, interventional procedures are variable based on the complexity of the case and the experience of each operator. Therefore, the dose delivered is not standardized and, in some specific cases, could reach levels high enough to produce deterministic effects to the patient. ${ }^{1}$ In such cases, the dose received by the operator is also presumably higher than usual. Thus, such situation requires radioprotection of both the patient and operator. To limit this risk, continuous and accurate dose information is desirable for the operator. In general, diagnostic X-ray images should be taken with the highest kilo voltages $(\mathrm{kV})$ and the lowest milli-ampere-second (mA.s), in an appropriate range, to produce an image with acceptable contrast and noise to give valuable diagnostic information. Therefore, the skin dose depends altogether on the tube tension $\mathrm{kV}$, exposure technique, mA.s, collimation (filed size) and filtration as well as the medical technique used for the procedure. Currently, there are several detectors available to monitor the skin dose during interventional radiology. ${ }^{2,3}$ In this article, the methods to measure skin dose are presented. Additionally, the main advantages and disadvantages of each method are discussed.

\section{Dose monitoring methods}

The methods to monitor the dose in radiology can be classified into two categories: direct and indirect measurements. For direct measurements, a dosimeter is placed on the skin of the patient, whereas for indirect measurements, calculation is done using quantities derived from the radiology machine parameters, thus providing basically the kerma in air. Figure 1 shows the dose monitoring methods used for interventional radiology.

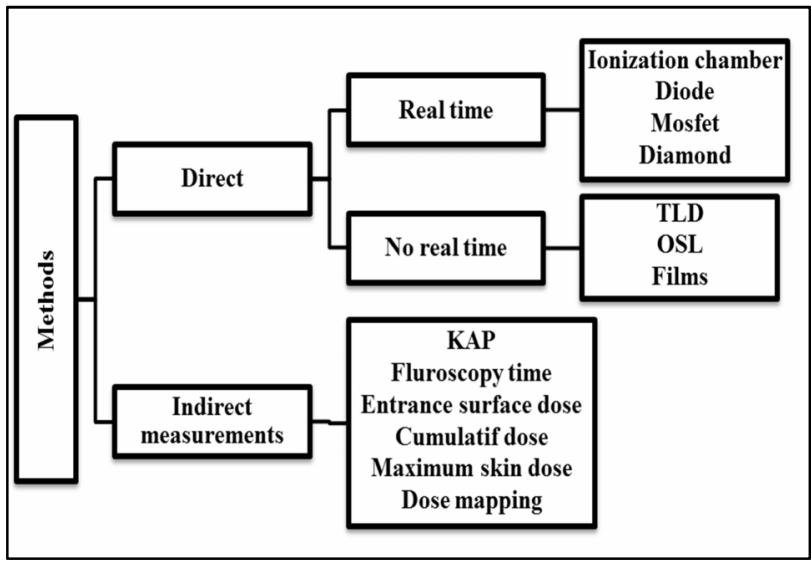

FIG. 1: Dose monitoring methods used in fluoroscopy and radiology. TLD = Thermo luminescent dosimeter; OSL = Optically stimulated luminescence; KAP = Kerma-area product. 


\section{Direct measurements}

The direct measurement can be performed using radiation dosimeters. In the following section, we provide an overview of all dosimeters that can be used for interventional radiology. We separated the dosimeters into "real time" and "no real time" dosimeters. Table 1 shows the main dosimeters used in radiology associated with their advantages and disadvantages. Figure 2 shows different real time dosimeters such as ionization chamber, diode, and optical fiber as well as the no real time dosimeters such as TLD and OSL.

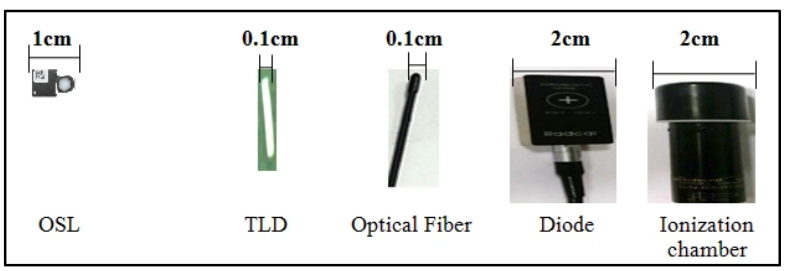

FIG. 2: Presentation of real time dosimeters such as ionization chamber, diode, optical fiber and not real time dosimeters such as TLD and OSL (Landauer Europe SAS).

\section{Real time dosimeters}

\section{Ionization chamber}

The chamber includes a gas-filled cavity with positive and negative electrodes with a voltage. Ionization chambers measure the amount of radiation passing through the cavity. The ionization chamber is connected via a cable with an electrometer to make the measure. Ionization chambers are the reference dosimeters for radiology and can be used for quality assurance and cross-calibration of other dosimeters. The International Atomic Energy Agency (IAEA) recommends two types of ionization chamber for radiology: cylindrical or plane parallel chambers.

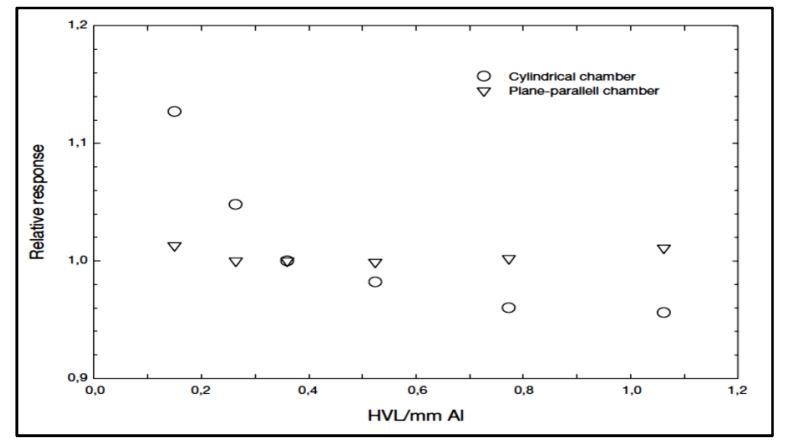

FIG. 3: Variation of relative response of a plane parallel chamber and a cylindrical chamber as a function of the first HVL of low energy $\mathrm{X}$-ray beams.

The most common type of ionization chamber for diagnostic radiology measurement of air kerma is a plane parallel chamber. Plane parallel ionization chambers (parallel plate) use two parallel, flat electrodes, separated by a few millimeters $(\mathrm{mm})$. The sensible volumes for available ionization chambers (Radcal $\left.{ }^{\circledR}\right)$ for interventional fluoroscopy are 0.6 or $0.18 \mathrm{cc}$. The ranges of measurable radiation dose are $(1 \mu \mathrm{Gy}-$
$5 \mathrm{kGy})$ and $(2 \mu \mathrm{Gy}-17 \mathrm{kGy})$, respectively for chambers with active volumes $0.6 \mathrm{cc}$ and $0.18 \mathrm{cc}$. The range of quantitative values for energy dependence is $\pm 5 \%$, and for dose-rate is $2 \%$. The Figure 3 shows the variations of relative response of a plane parallel chamber and a cylindrical chamber as a function of the first Half Value Layer HVL measured using Aluminum ( $\mathrm{Al})$ in $\mathrm{mm}$ as an attenuator of low energy $\mathrm{X}$-ray beams. Robin et al., ${ }^{4}$ showed that the cylindrical ionization chamber (type: Farmer chamber) has an energy response variation within $2-3 \%$ for beam energies ranging from 50-300 $\mathrm{kV}$.

\section{Diode dosimeter}

The diodes are based on a $\mathrm{p}-\mathrm{n}$ junction between the $\mathrm{p}$-type and n-type parts of a semiconductor. The diodes are more sensitive and had small size compared to ionization chambers. The irradiation of a semiconductor induces electron-hole pairs making the junction to become conductive and producing a current, which increases with the rate of electron-hole pair's production. The signal generated depends on the ionizing properties of the radiation and on its ability to penetrate into the junction. The diode responses have energy dependence and need correction factors. The silicon $(Z=14)$ is not tissue equivalent, compared to about a $Z$ effective of 7.4 for tissue. The interaction of the radiation with the diode varies according to energy. The size of the signal generated depends on the ionizing properties of the radiation and on its ability to penetrate the junction. The amount of ionization reaching the junction may also depend on the cross sectional area of the junction in relation to the incidence of the beam. Diode shows some energy dependence, a variation in dose response with temperature, dose rate, and angular incidence with the beam. Philippe et al. ${ }^{5}$ showed that the lower measurable dose is about 7.7 mGy using Si-diode and the maximum discrepancy between the Si-diode without filtration and the ionization chamber response is equal to $20 \%$ for energy beam ranged from 55-110kV.

\section{Metal-Oxide Semiconductor Field Effect Transistor (MOSFET) dosimeter}

The MOSFET is a miniature silicon transistor and has an excellent spatial resolution. Recently, the characteristics of MOSFET for medical use in X-ray beams were evaluated. ${ }^{6,7,8}$ The use of MOSFET needs correction factors for energy-dependence and field size and a verification of the sensitivity. The MOSFET is not tissue equivalent and has a higher $\mathrm{Z}$ showing higher sensitivity and energy dependence. Bower et al. ${ }^{9}$ showed that the MOSFET dosimeter (Thomson/Nielsen TN-RD-19) has a high sensitivity showing an increased dose response from $0.3 \mathrm{mV} / \mathrm{mGy}$ to about $4 \mathrm{mV} / \mathrm{mGy}$ at diagnostic energy ranges.

Peet et al. ${ }^{7}$ showed that the minimum measured dose using MOSFET is $1.5 \mathrm{mGy}$ compared with $4 \mathrm{mGy}$ for the standard dosimeter, and it had a linear response with absorbed dose in 
air, dose rate and energy dependence. Christian et al. ${ }^{10}$ showed that the response of MOSFET (TN-502RDI) was linear with dose in the range from 0.2 to $2 \mathrm{~Gy}$ for $\mathrm{X}$-ray ranged from 80 to $250 \mathrm{kV}$. They recommended reading the MOSFET signal during the first $15 \mathrm{~min}$ after irradiation. The temperature dependence of the detector signal was $0.3 \% /{ }^{\circ} \mathrm{C}$ in temperature range between 22 and $40^{\circ} \mathrm{C}$. The variation of the measuring signal with beam incidence amounts to $\pm 5 \%$. They showed that the agreement between MOSFET and TLD measurements was within 3\%. However, MOSFET has the disadvantage that it is visible in radiographs. ments because of their small size, tissue equivalence and resistance to the radiation damage. Diamond detectors exhibit high sensitivity and high resolution with a sensitive volume of $\left(1 \mathrm{~mm}^{3}\right)$. However, the use of the diamond for low energy $\mathrm{X}$-ray needs a correction factors for dose rate and energy which can be reached to up to $12 \% .{ }^{11}$ The diamond can be used to measure depth doses for X-ray beam with a good agreement with ionization chambers. ${ }^{12}$ Recently, the diamond dosimeters have been evaluated and used for proton therapy, stereotactic radiosurgery beams, and megavoltage X-ray fields. ${ }^{13-16}$

\section{Diamonds dosimeter}

The diamonds dosimeters are suitable for in vivo measure-

TABLE 1: The main advantages and disadvantages of dosimeters used in radiology.

\begin{tabular}{|c|c|c|}
\hline Dosimeters & Advantage & Disadvantages \\
\hline $\begin{array}{l}\text { Ionization } \\
\text { chamber }\end{array}$ & $\begin{array}{l}\text { Instant readout } \\
\text { Precise } \\
\text { Recommended for beam calibration }\end{array}$ & $\begin{array}{l}\text { Connecting cable required } \\
\text { High voltage supply required } \\
\text { Many corrections required for high energy dosimetry } \\
\text { Large and visible }\end{array}$ \\
\hline Diode & $\begin{array}{l}\text { Instant readout } \\
\text { Do not need to be connected to a high voltage } \\
\text { supply } \\
\text { High sensitivity }\end{array}$ & $\begin{array}{l}\text { Not tissue equivalent } \\
\text { Requires correction factors for temperature, dose rate, } \\
\text { energy, angular dependence } \\
\text { Connecting cable required } \\
\text { Rather large and visible }\end{array}$ \\
\hline MOSFET & $\begin{array}{l}\text { Instant readout } \\
\text { High sensitivity } \\
\text { Rather small }\end{array}$ & $\begin{array}{l}\text { Connecting cable usually required } \\
\text { Requires correction factors }\end{array}$ \\
\hline Diamond & $\begin{array}{l}\text { Tissue equivalent } \\
\text { Small volume } \\
\text { Excellent spatial resolution } \\
\text { No directional dependence } \\
\text { No temperature dependence }\end{array}$ & $\begin{array}{l}\text { Dose rate dependence } \\
\text { Energy dependence } \\
\text { Very expensive }\end{array}$ \\
\hline Optical fiber & $\begin{array}{l}\text { Instant readout } \\
\text { Small size } \\
\text { Lightweight }\end{array}$ & $\begin{array}{l}\text { Requires connecting cables } \\
\text { Requires photo-multiplicator } \\
\text { Energy dependence }\end{array}$ \\
\hline $\begin{array}{l}\text { Thermoluminescent } \\
\text { dosimeter (TLD) }\end{array}$ & $\begin{array}{l}\text { Small in size } \\
\text { Many TLDs can be exposed in a single exposure } \\
\text { Available in various forms } \\
\text { Some are tissue equivalent } \\
\text { Cheap } \\
\text { Could be introduced in anatomic cavities }\end{array}$ & $\begin{array}{l}\text { No instant readout } \\
\text { Fading: decrease of response } \\
\text { Accurate results require care and complex procedures } \\
\text { Readout and calibration are time consuming } \\
\text { Need of a heating system }\end{array}$ \\
\hline $\begin{array}{l}\text { Optically stimulated } \\
\text { luminescence (OSL) }\end{array}$ & $\begin{array}{l}\text { Small size } \\
\text { Could be introduced in anatomic cavities } \\
\text { No need to be heated }\end{array}$ & $\begin{array}{l}\text { Not instant readout } \\
\text { Temperature dependence } \\
\text { Need laser reading }\end{array}$ \\
\hline $\begin{array}{l}\text { Radiographic } \\
\text { film }\end{array}$ & $\begin{array}{l}\text { 2D dose mapping } \\
\text { Does not perturb the beam }\end{array}$ & $\begin{array}{l}\text { Not instant readout } \\
\text { Required dark room and developer } \\
\text { Need readout with a densitometer } \\
\text { Processing is difficult to control } \\
\text { Energy dependence } \\
\text { Useful for dose up to } \sim 2 \mathrm{~Gy} \\
\text { Disposable }\end{array}$ \\
\hline $\begin{array}{l}\text { Gafchromic } \\
\text { film }\end{array}$ & $\begin{array}{l}\text { 2D dose mapping } \\
\text { Able to find the maximal dose } \\
\text { Lower sensibility } \\
\text { Rather low cost }\end{array}$ & $\begin{array}{l}\text { Not instant readout } \\
\text { Need readout with a densitometer } \\
\text { Complex for analysis } \\
\text { Dependence on beam } \\
\text { quality and film orientation }\end{array}$ \\
\hline
\end{tabular}




\section{Optical fiber dosimeter}

Optical fiber dosimeter is based on the light resulting from the irradiation of a plastic scintillator. The light (scintillation photon) is guided and transmitted from the sensitive element to a photomultiplier tube (PMT) via a transmission fiber, and then the signal is analyzed by a computer. The use of a PMT allows a real time monitoring of the light output from dosimeter. The use of optic fibers in radiology has progressed in the recent years. Several studies evaluate the characteristics of optical fiber based dosimeters for radiology measurements. ${ }^{17-21}$ Theses dosimeters have a very small volume $(\sim 1$ $\mathrm{mm}^{3}$ ) and excellent tissue equivalence in terms of electron density and atomic composition. The main disadvantage is the noise signal produced in the light-guide by Cerenkov radiation for higher $\mathrm{MeV}$ and fluorescence for low energy $\mathrm{X}$-ray beam. The dosimeters are almost no energy dependent and independent of dose rate showing a good reproducibility and long term stability. Optical fiber dosimeter can be used from $10 \mu \mathrm{Gy} / \mathrm{min}$ with ophthalmic plaque dosimetry to about $10 \mathrm{~Gy} / \mathrm{min}$ for external beam dosimetry. This dosimeter has no significant directional dependence and it does not need correction factors for temperature or pressure. ${ }^{22}$ Lessard et al., showed that the energy dependence can be corrected using mass-energy-absorption coefficients determined with Monte Carlo calculations and measured $\mathrm{x}$-ray spectra information. ${ }^{23}$

\section{No real time dosimeters}

\section{Thermo luminescent dosimeter (TLD)}

The thermo luminescent dosimetry is based on the physical property of certain crystals to emit light when they are heated after having been irradiated. The quantity of light is proportional to the energy deposited during irradiation. The detection system consists of TLD detectors, a heating system with a light measurement device. After each heating-reading cycle the TLD can be used again. Currently, some materials such as $\mathrm{LiF}-100, \mathrm{CaSO}_{4}: \mathrm{Tm}$ or $\mathrm{LiF}: \mathrm{Mg}-\mathrm{Cu}$ are the most used detectors to measure the skin dose of patients or exposed workers. ${ }^{24}$ TLDs are available in various forms (e.g. powder, chips, rods, and ribbons) and made of various materials. Dosimeters most commonly used in medical applications are based on lithium fluoride doped with magnesium and titanium (LiF:Mg,Ti), because of its tissue equivalence $\left(Z_{\text {eff }}=8\right)$ and high sensitivity. It can be used to measure the dose ranging from $10 \mu \mathrm{Gy}$ to 10 $\mathrm{kGy}$. Table 2 gives basic characteristics of most used TLD according to IAEA. ${ }^{25}$ It can be seen in Table 2 that not all TLDs are tissue-equivalent such as $\mathrm{CaSO}_{4}$, which is energy dependent and needs a correction factor. The $\mathrm{CaSO}_{4}: \mathrm{Dy}$ is also more responsive to low-energy and has an effective atomic number of 15.3, which is not tissue-equivalent. The TLD-100H dosimeter is made from a nearly tissue equivalent material with an effective atomic number of 8.2 showing a better TLD dosimeter for dose measurements. The detection range of the TLD-100H dosimeter is $1 \mathrm{mGy}$ to $10 \mathrm{~Gy}$. It is more sensitive and has a lower energy response in $\mathrm{kV}$ beam ranges.
TABLE 2: Dosimetric characteristics of three TLD.

\begin{tabular}{|c|c|c|c|c|}
\hline TLD & $\begin{array}{l}\text { Glow peak } \\
\left(\mathrm{C}^{\circ}\right)\end{array}$ & Zeff & $\begin{array}{l}\text { Relative } \\
\text { sensitivity }\end{array}$ & $\begin{array}{l}\text { Linear range } \\
(\mathrm{Gy})\end{array}$ \\
\hline LiF:Mg,Ti & 210 & 8.14 & 1 & $5 \times 10^{-5}$ to 1 \\
\hline $\mathrm{Al}_{2} \mathrm{O}_{3}: \mathrm{C}$ & 250 & 10.2 & 30 & $10^{-4}$ to 1 \\
\hline $\mathrm{CaSO}_{4}: \mathrm{Dy}$ & 220 & 15.3 & $30-40$ & $10^{-6}$ to 30 \\
\hline
\end{tabular}

Optically-stimulated luminescence (OSL)

OSL is based on a similar principle to that of the TLD. ${ }^{26} \mathrm{In}-$ stead of heating, it is the light from a laser which is used to release the trapped energy and generate the luminescence. The most common OSL dosimeter is aluminum oxide doped with carbon $\left(\mathrm{Al}_{2} \mathrm{O}_{3}: \mathrm{C}\right)$. $\mathrm{Al}_{2} \mathrm{O}_{3}: \mathrm{C}$ has a higher effective atomic number $Z_{\text {eff }}=11.4$ compared to 7.4 for tissue and the photoelectric effect is dominant at low energies ranged from 10 to 20 $\mathrm{kV}$. Recently, George et al. ${ }^{27}$ showed that a correction factor for energy dependence should be mad for $\mathrm{kV}$ X-ray beam ranging from 60 to $125 \mathrm{kV}$. Noteworthy, OSL, if appropriately instrumented, can deliver the dose information immediately after the irradiation, in conditions close, but not equal, to real time measure.

Using the $\mathrm{kV}$ beams, the response of $\mathrm{Al}_{2} \mathrm{O}_{3}: \mathrm{C}$ relative to $6 \mathrm{MV}$ increases with decreasing energy due to the higher atomic number of aluminum oxide 11.2 relative to water. ${ }^{28}$ The response of detector is independent of energy for megavoltage photons, electrons, and protons. Aznar et al. ${ }^{29}$ evaluated the properties of OSL using small detector $\left(0.1 \times 0.1 \times 0.2 \mathrm{~cm}^{3}\right)$ for real-time dosimetric. The detector was connected to readout system by an optical fiber. They showed a difference of $0.6 \%$ for detector response between 6 and $18 \mathrm{MV}$ photons, a $0.3 \%$ variation in dose rate from 0.88 to $5.1 \mathrm{~Gy} / \mathrm{min}$, an angular dependence of about $1.3 \%$ from $45^{\circ}$ to $320^{\circ}$ and less than a $1 \%$ change in response for field sizes from $5 \times 5$ to $15 \times 15 \mathrm{~cm}^{2}$.

\section{Radiographic film}

$\mathrm{X}$-ray film consists of a base of thin plastic sheet with a radiation sensitive emulsion (silver bromide $\mathrm{AgBr}$ grains suspended in gelatin) coated uniformly on one or both sides of the base. Ionization of $\mathrm{AgBr}$, as a result of radiation interaction, forms the latent image in the film. After the irradiation, the film should be developed, then the image becomes visible (film blackening) followed by the measurement of the optical density using a densitometer. ${ }^{22}$ The radiographic film has a working range from $0.01 \mathrm{~Gy} \sim 2 \mathrm{~Gy}$ which is a rather narrow range that can be exceeded in the highest dose fluoroscopic procedures. The use of film requires a calibration.

\section{Radiochromic film}

The most commonly used radiochromic film is the GafChromic $^{\mathrm{TM}}$ film. It contains a special dye that gets polymerized upon exposure to radiation. The polymer absorbs light and the transmission of light through the film can be measured. ${ }^{30}$ It measures the quantities of dose at skin during fluoroscopy and provides 2D dose mapping. After the irradiation the film must be developed using a scanning densitom- 
eter and a complex calibration proceeding. Figure 4 shows a Gafchromic EBT ${ }^{\mathrm{TM}}$ film before and after irradiation. Recently, McCabe et al. ${ }^{31}$ showed that the calibration curves depend on film orientation facing the $\mathrm{X}$-ray source, $\mathrm{kV}$, and patient-equivalent backscattering. They showed that the film calibration curves created under free-in-air conditions may be used to measure dose from fluoroscopic quality X-ray beams, including patient backscatter with an error less than the uncertainty of the calibration in most cases. The overall uncertainty of the air kerma map calculated from the calibration curves and corrected for scanner measurement non-uniformity was $7.1 \%$.

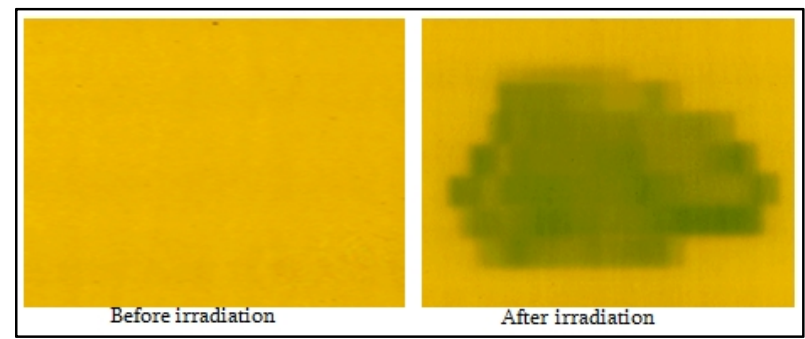

FIG. 4: Gafchromic-EBT ${ }^{\mathrm{TM}}$ film before and after irradiation.

\section{Indirect and complex measurements}

\section{Kerma-area product (KAP)}

$\mathrm{KAP}$ is the air kerma averaged over the area of the X-ray in a plan perpendicular to the beam axis multiplied by the area of the beam in the same plan. It is expressed as:

$$
\mathrm{KAP}\left(\mathrm{mGy} \cdot \mathrm{cm}^{2}\right)=\text { kerma } \times \text { area }
$$

The effective dose (E) can be calculated as:

$$
\mathrm{E}=\mathrm{F}_{\mathrm{KAP}} \times \mathrm{KAP}
$$

where, FKAP $\left[\mathrm{mSv} \cdot \mathrm{mGy}^{-1} \cdot \mathrm{cm}^{-2}\right]$ is the transformation factor that has been calculated for different types of X-ray procedures with regards to the beam geometry and beam quality.

KAP is one of the dose descriptor, which represents the radiation risk. It is helpful tool in providing dose information, which can used to predict the total irradiation to a patient, but the information may not be sufficient for the prediction of deterministic effect. KAP measures the total radiation emitted from the fluoroscopic system entering the patient. KAP can be measured at the level of the tube diaphragms using ionization chambers or calculated depending on parameters such as $\mathrm{kV}$ and $\mathrm{mA}$.s. Transmission ionization chambers can be used as detectors for dose-area product or KAP meters. The transmission ionization chamber generally consists of layers of PMMA coated with conductive material. Graphite, a commonly used coating material, is close to air equivalent and introduces low energy dependence for air kerma measurements. Graphite coating is, however, incon- venient in transmission chambers since it is non-transparent to light. ${ }^{25}$

To estimate the air kerma, at a given distance, we need the specific yield of the X-ray tube ( $\mathrm{mGy} / \mathrm{mAs}$ ) depending on the tube voltage and beam filtration. Therefore, KAP is independent of the distance from X-ray source, whereas the air kerma decreases with the inverse square law. The X-ray equipment displays a calculated KAP at the level of the collimator diaphragm based on the X-ray tube output, tube voltage, current-time product and opining area of diaphragm. Calculation of KAP based upon $\mathrm{kV}$ and $\mathrm{mA}$.s only may not be sufficient since there may be a few more parameters, such as filtration, which may affect the KAP.

\section{Fluoroscopy time}

Fluoroscopy time is the tracking of the total irradiation time during fluoroscopy procedure to estimate the total dose to the skin. However, the fluoroscopy time alone is a poor indicator of radiation dose in interventional radiology. Fluoroscopy time can give only relative idea of the dose in various cases and it can't give real dose.

\section{Entrance surface dose}

It is the absorbed dose to air at point of intersection of the $\mathrm{X}$-ray beam axis with entrance surface of patient including backscattered factor (B). The entrance dose is expressed in $\mu \mathrm{Gy}$. The B factor can be calculated using Monte Carlo simulation using physical phantom. ${ }^{25,} 32$ According to the type of instrument or method used to measure the entrance dose, this entrance surface dose could be either a real time or a no real time measure.

\section{Cumulative dose to interventional reference point (IRP)}

The International Electro-technical Commission (IEC) introduced the concept of cumulative dose. It is the air kerma value at a specific point in space relative to the fluoroscopic gantry during a procedure. It shows a cumulative approximation of the total radiation dose to the skin, summed over the entire procedure. Depending on the patient's size, the table height, and the angulation of the beam, the IRP may be outside the patient, may coincide with the skin surface, or may be inside the patient. ${ }^{33}$ IRP is thus more a technical characteristic of the equipment than operational information of the exposure of a real patient.

\section{Dose mapping}

This method allows visualizing the dose distribution into the area which was irradiated. The $2 \mathrm{D}$ dose mapping can be realized, for instance, using a film.

\section{Maximum skin or peak skin dose}

It is the maximum dose received by the patient on the skin surface in the irradiation area. 


\section{Discussion}

Interventional radiology procedures are performed using $\mathrm{X}$-ray beams with peak voltage (often quoted as $\mathrm{kVp}$ ) ranging from 50 to $125 \mathrm{kV}$ and with additional filtration. This depends on the clinical use of the radiation. In complicated and long procedures the fluoroscopy delivered dose can be associated with a risk of radiation injury to the skin and hair of the patient. ${ }^{34}$ Along the same line, in the author experience the scattered radiation doses to eye lenses for the radiologist and operators for radiation protection may exceed the threshold for deterministic effects after several years of work if specific additional radiation protection devices are not used. The deterministic effect shows the dose threshold value, and the effect is not observable below dose threshold value. Therefore, the monitoring of the dose during the procedures is useful and could sometimes be critical for patient and operator. Interestingly enough, one should consider two different approaches. On one hand, various indirect means could offer a registered information for traceability and remote or delayed assessment of the quality insurance or the exposure level with no immediate use as a continuous feedback; and on the other hand, explicit procedure and real time accepted information that could participate to the technical environment of the operator to control and conduct his work. These are two very different goals that could deserve different techniques and specific devices. A kind of voluntary approach of real time control demanded and accepted by the dose aware operators would have more chance to be adopted and actually be used than an imbedded standard device packaged with the whole interventional system.

\section{Critical comparison of the methods}

In this review, we showed that there are two types of methods to monitor the skin dose. The use of directs dosimeters for measuring the dose require a calibration procedure at clinical condition according to ICRU and IAEA. If the response of dosimeters depends on various factors such as X-ray energy, angular, and temperature, a correction factor must be established before using the dosimeters in clinical applications. Therefore, the results of the dosimeter must show a good repeatability and reproducibility for clinical use. The international norms recommend that the variation of dosimetric instrument in the diagnostic radiology must not exceed 3\% for stability and repeatability. ${ }^{35}$ The calibration and correction factors should be measured using a reference ionization chamber. The ionization chamber shows the advantage of low energy dependence and of few correction factors. However, it can be seen in Table 1 that the dosimeters are not equal at the point of view of their use. All real-time dosimeters available in clinical are one dimensional (1D) and allows only a one point measurement. It is interesting to note that a detector having a small size may be an advantage only in radiography and radiotherapy and it may not be advantageous in interventional radiology and interventional cardiology, where there may be a lot of movement of patient with respect to the X-ray field, and this could result in single small detector missing the X-ray field.

Therefore, the bi-dimensional (2D) dosimeters such as radiographic and radiochromic films appear useful for overall measurement. In this case the film should be placed on the patient skin at the region of entrance beam before the procedures. Then the film must be developed for showing a 2D dose map for skin dose and peak skin dose (PSD). ${ }^{36}$ The fundamental disadvantages of films are lack of real time measurement and inability to record the radiation dose outside the film. However, 2D dosimeters are good for showing the accumulated dose after exposure, registering, and reporting the dose.

The indirect methods using the KAP quantity shows air kerma without scattering dose. Currently, the machines include KAP measures, which indicate the dose in units of air kerma. This method approximates the point at which the $\mathrm{X}$-ray beam enters the skin and displays the dose. The skin dose is approximately $40 \%$ greater than air kerma. ${ }^{37}$ The limit of this method is that the machine shows only one value regardless of the distance between the source and-dosimeter. Also, KAP does not include beam position and patient size and motion. However, KAP has effect of collimation since it includes the field size. In interventional radiology the X-ray output depends upon the thickness of the body part scanned due to the automatic exposure control (AEC) mechanism. In such a scenario, KAP does take thickness of the body part into account. As a result the KAP under-estimates the dose to the patient. Therefore, to estimate the entrance dose to skin, a backscatter factor should be used. Appendix A in ICRU report 74 presents more information. The factor for $15 \mathrm{~cm}$ depth is the most common and conventional factor for dosimetry of $\mathrm{X}$-ray, and it varies from 1.24 to 1.67. It also depends on the tube voltage, filtration, and field size. However, backscatter factor does not take into account the phantom constitutive mater, which could introduce 3 to $10 \%$ of correction, depending on the field size and the half value layer. ${ }^{38}$

\section{Recommendation and perspective}

The use of real-time skin dose mapping for dose measurement in fluoroscopy proceeding should be recommended. The real time measurement would help the operator to change his/her behavior and adopt lower doses. However, the skin dose mapping requires an advanced technology and it needs to take into account the patient anatomy submitted to the procedure. Johnson et al. ${ }^{39}$ proposed software to visualize the patient skin dose. This software simulates the patient with a predefined phantom and uses derived quantities measured from the machine to realize the dose map. ${ }^{39}$ The dose map was carried out using a software system. ${ }^{39}$ The skin dose mapping program operates by translating the reference point air kerma to the location of the patient's skin using geometric 
parameters extracted from the newly released radiation dose structured report. The patient surface is represented by a computational phantom defined as a set of points in three dimensional spaces.

Sandblom et al. ${ }^{40}$ showed a significant dose reduction for fluoroscopy guided procedures for cardiology using the system DoseAware ${ }^{\complement}$ (Personal Dose Meter System, Philips Healthcare, Best, The Netherlands) in real time visualization. It includes solid state detectors with wireless connection and showing the scatter dose rate. ${ }^{40,41}$ The dose map measured by a system includes a solid-state detectors equipped with a wireless connection that sends the scatter dose rate and cumulative scatter dose readings to a base station.

Recently Bordier et al. ${ }^{42}$ proposed a dose map method to show the local dose in the patient. In this study ${ }^{42}$, the local dose was calculated in $1 \mathrm{~cm}^{2}$ areas depending on the estimated air kerma, table, gantry positions and system settings, taking into account the table and positioning devices attenuations and estimated backscatter from the patient. The local doses are cumulated for each location of the patient during the clinical procedure. Then, a Gafchromic XR RV3 film was used to measure the cumulated dose and dose map in $1 \mathrm{~cm}^{2}$. The accuracy between calculated method and measured dose was within $24.9 \% .42$

\section{Conclusion}

This paper presents a review of monitoring methods for skin dose that can be used for radiography and fluoroscopy. The direct and indirect methods were discussed. We also proposed a reflection on the new technology and the future methods. A perfect method for skin dose measurement is not available for clinical use yet. A real time dose mapping method using the anatomy of the patient would be the ideal method for monitoring the dose, which can help in predicting the location and risk of skin or hair injury after irradiation procedures. This is, however, a supplementary level of complexity to master during complex and sometime stressful procedures.

\section{Acknowledgement}

The authors acknowledge the financial support of French National Research Agency (ANR-11-TECS-018) for research funding.

\section{Conflict of interest}

The authors declare that they have no conflicts of interest. The authors alone are responsible for the content and writing of the paper.

\section{References}

1. Vano E, Gonzalez L, Fernández JM, Haskal ZJ. Eye lens exposure to radiation in interventional suites: caution is warranted. Radiology 2008; 248:945-53.

2. Fletcher S W, Kuan H M, Miller D, et al. Techniques to estimate radiation dose to skin during fluoroscopically guided procedures Skin Dose Measurements. AAPM 2002.

3. Balter S. Methods for measuring fluoroscopic skin dose. Pediatr Radiol 2006; 36:136-40.

4. Hill R, Healy B, Holloway L, et al. Advances in kilovoltage x-ray beam dosimetry. Phys Med Biol 2014; 59:R183-231.

5. Meyer P, Regal R, Jung M, et al. Feasibility of a semiconductor dosimeter to monitor skin dose in interventional radiology. Med Phys 2001; 28:2002-6.

6. Ehringfeld C, Schmid S, Poljanc K, et al. Application of commercial MOSFET detectors for in vivo dosimetry in the therapeutic $\mathrm{x}$-ray range from $80 \mathrm{kV}$ to 250 kV. Phys Med Biol 2005; 50: 289-303.

7. Peet DJ, Pryor MD. Evaluation of a MOSFET radiation sensor for the measurement of entrance surface dose in diagnostic radiology. Brit J Radiol 1999; 72: 562-8.

8. Cheung T, Buston MJ, Yu PK. MOSFET dosimetry in-vivo at superficial and orthovoltage $\mathrm{X}$-ray energies. Australas Phys Eng Sci Med 2003; 26:82-4.

9. Bower M W, Hintenlang D E. The characterization of a commercial MOSFET dosimeter system for use in diagnostic X ray. Health Phys 1998; 75: 197-204.

10. Ehringfeld C, Schmid S, Poljanc K, et al. Application of commercial MOSFET detectors for in vivo dosimetry in the therapeutic $\mathrm{x}$-ray range from $80 \mathrm{kV}$ to 250 kV. Phys Med Biol 2005; 50:289-303.

11. Hugtenburg RP, Johnston K, Chalmers GJ, Beddoe $\mathrm{AH}$. Application of diamond detectors to the dosimetry of 45 and $100 \mathrm{kvp}$ therapy beams: comparison with a parallel-plate ionization chamber and Monte Carlo. Phys Med Biol 2001; 46:2489-501.

12. Knoos T, Munck Af, Rosenschold P, Wieslander E. Modelling of an orthovoltage X-ray Therapy Unit with the EGSnrc Monte Carlo package. J Phys 2007: Conf. Ser. 74021009.

13. Mandapaka AK, Ghebremedhin A, Patyal B, et al. Evaluation of the dosimetric properties of a synthetic single crystal diamond detector in high energy clinical proton beams. Med Phys 2013; 40:121702.

14. Heydarian M, Hoban PW, Beddoe AH. A comparison of dosimetry techniques in stereotactic radiosurgery. Phys Med Biol 1996; 41:93-110.

15. Yin Z, Hugtenburg RP, Green S, Beddoe AH. Dose responses of diamond detectors to monoenergetic x-rays. Nucl Instrum Methods Phys 2004; 213 : 646-56. 
16. Ciancaglioni I, Marinelli M, Milani E, et al. Dosimetric characterization of a synthetic single crystal diamond detector in clinical radiation therapy small photon beams. Med Phys 2012; 39:4493-501.

17. Ding GX, Malcolm AW. An optically stimulated luminescence dosimeter for measuring patient exposure from imaging guidance procedures. Phys Med Biol 2013; 58:5885-97.

18. Hyer DE, Fisher RF, Hintenlang DE. Characterization of a water-equivalent fiber-optic coupled dosimeter for use in diagnostic radiology. Med Phys 2009; 36:1711-6.

19. Lacroix F, Archambault L, Gingras L, et al. Clinical prototype of a plastic water-equivalent scintillating fiber dosimeter array for QA applications. Med Phys 2008; 35:3682-90.

20. Yoo WJ, Jeon D, Seo JK, et al. Development of a scintillating fiber-optic dosimeter for measuring the entrance surface dose in diagnostic radiology. Radiat Meas 2013; 48: 29-34.

21. Yoo WJ, Shin SH, Jeon D, et al. Development of a fiber-optic dosimeter based on modified direct measurement for real-time dosimetry during radiation diagnosis. Meas Sci Technol 2013; 24: 094022.

22. Podgorsak EB. Radiation oncologyphysics: A handbook for teachers and students. International atomic energy agency. VIENNA, 2005.

23. Lessard F, Archambault L, Plamondon M, et al. Validating plastic scintillation detectors for photon dosimetry in the radiologic energy range. Med Phys 2012; 39:5308-16.

24. Dong SL, Chu TC, Lan GY, et al. Characterization of high-sensitivity metal oxide semiconductor field effect transistor dosimeters system and LiF:Mg,Cu,P thermoluminescence dosimeters for use in diagnostic radiology. Appl Radiat Isot 2002; 57:883-91.

25. International Atomic Energy Agency. IAEA Report $\mathrm{No}^{\circ}$ 457: Dosimetry in diagnostic radiology: an international code of practice. Vienna, 2007.

26. Akselrod MS, Lucas AC, Pofl JC, Mckeever SWS. Optically stimulated luminescence of $\mathrm{Al}_{2} \mathrm{O}_{3}$. Radiation measurement 1998; 29:391-9.

27. Ding GX, Malcolm AW. An optically stimulated luminescence dosimeter for measuring patient exposure from imaging guidance procedures. Phys Med Biol 2013; 58:5885-97.

28. Reft CS. The energy dependence and dose response of a commercial optically stimulated luminescent detector for kilovoltage photon, megavoltage photon, and electron, proton, and carbon beams. Med Phys 2009; 36:1690-9.

29. Aznar MC, Andersen CE, Bøtter-Jensen L, et al. Real-time optical-fibre luminescence dosimetry for radiotherapy: physical characteristics and applications in photon beams. Phys Med Biol 2004; 49:1655-69.
30. Niroomand-Rad A, Blackwell CR, Coursey BM, et al. Radiochromic film dosimetry: recommendations of AAPM Radiation Therapy Committee Task Group 55. American Association of Physicists in Medicine. Med Phys 1998; 25:2093-115.

31. McCabe BP, Speidel MA, Pike TL, Van Lysel MS. Calibration of GafChromic XR-RV3 radiochromic film for skin dose measurement using standardized $\mathrm{x}$-ray spectra and a commercial flatbed scanner. Med Phys 2011; 38:1919-30.

32. International Commission on Radiation Units and Measurements. ICRU Report $\mathrm{No}^{\circ} 74$ : Patient dosimetry for $\mathrm{x}$ rays used in medical imaging. Journal of the ICRU2005; 5 (2).

33. International Electro technical Commission. IEC 60601: Medical electrical equipment part 2-43: particular requirements for the safety of $\mathrm{x}$-ray equipment for interventional procedures. Geneva: IEC, 2000.

34. Balter S, Hopewell JW, Miller DL, et al. Fluoroscopically guided interventional procedures: a review of radiation effects on patients' skin and hair. Radiology 2010; 254:326-41.

35. International Electro technical Commission. IEC 61674: Medical Electrical Equipment- Dosimeters with ionization chambers and/or semi-conductor detectors as used in $\mathrm{X}$ ray diagnostic imaging. Geneva: IEC, 2012.

36. Vañó E, Guibelalde E, Fernández JM, et al. Patient dosimetry in interventional radiology using slow films. Br J Radiol 1997; 70:195-200.

37. Balter S, Schueler BA, Miller DL, et al. Radiation doses in interventional radiology procedures: the RAD-IR Study. Part III: Dosimetric performance of the interventional fluoroscopy units. J Vasc Interv Radiol 2004; 15:919-26.

38. Benmakhlouf H, Fransson A, Andreo P. Influence of phantom thickness and material on the backscatter factors for diagnostic x-ray beam dosimetry. Phys Med Biol 2013; 58:247-260.

39. Johnson PB, Borrego D, Balter S, et al. Skin dose mapping for fluoroscopically guided interventions. Med Phys 2011; 38:5490-9.

40. Sandblom V, Mai T, Almén A, et al. Evaluation of the impact of a system for real-time visualisation of occupational radiation dose rate during fluoroscopically guided procedures. J Radiol Prot 2013; 33:693-702.

41. Vano E, Fernandez JM, Sanchez R. Occupational dosimetry in real time. Benefits for interventional radiology. Radiation Measurements 2011; 46: 1262-5.

42. Bordier C, Klausz R, Desponds L. Patient dose map indications on interventional $\mathrm{x}$-ray systems and validation with GafchromicXR-RV3 film. Radiat Prot Dosimetry 2014; pii: ncu181. 